\title{
Retraction Note to: Biosynthesis of colloidal silver nanoparticles: Their characterization and potential antibacterial activity
}

Chikkapura Shekarappa Shivananda ${ }^{1}{ }^{1}$ Department of Studies in Physics, Mangalore University, Mangalagangotri, Mangalore - 574

Sangappa Asha ${ }^{1}$

Rajappa Madhukumar ${ }^{1}$

Sreedharamurthy Satish ${ }^{2}$

Badiadka Narayana ${ }^{3}$

Kullaiah Byrappa ${ }^{4}$

Youjiang Wang ${ }^{5}$

Yallappa Sangappa*,1,5
199, Karnataka, India

${ }^{2}$ Department of Microbiology, University of Mysore, Manasagangotri, Mysore - 570 006, Karnataka, India

${ }^{3}$ Department of Studies in Chemistry, Mangalore University, Mangalagangotri, Mangalore - 574 199, Karnataka, India

${ }^{4}$ Department of Materials Science, Mangalore University, Mangalagangotri, Mangalore - 574 199, Karnataka, India

${ }^{5}$ School of Materials Science and Engineering, Georgia Institute of Technology, Atlanta, GA - 30332, USA

Retraction Note: The Editor-in-Chief has retracted this article [1] because it significantly overlaps with a previously published article from the same authors [2]. Yallappa Sangappa disagrees with this retraction. The other authors have not responded to correspondence regarding this retraction.

[1] Chikkapura Shekarappa Shivananda ${ }^{1}$, Sangappa Asha ${ }^{1}$, Rajappa Madhukumar ${ }^{1}$, Sreedharamurthy Satish $^{2}$, Badiadka Narayana ${ }^{3}$, Kullaiah Byrappa ${ }^{4}$, Youjiang Wang ${ }^{5}$, and Yallappa Sangappa ${ }^{*, 1,5}$, Biosynthesis of colloidal silver nanoparticles: Their characterization and potential antibacterial activity. Macromol. Res., 24, 684 (2016). https://doi.org/10.1007/s13233-016-4086-5.

[2] C. S. Shivananda, S. Asha, R. Madhukumar, S. Satish, B. Narayana, K. Byrappa, Y. Wang, and Y. Sangappa, Biomed. Phys. Eng. Express, 2, 035004 (2016).

The online version of the original article can be found at https://doi.org/ $10.1007 / \mathrm{s} 13233-016-4086-5$

*Corresponding Author: Yallappa Sangappa (syhalabhavi@yahoo.co.in) 